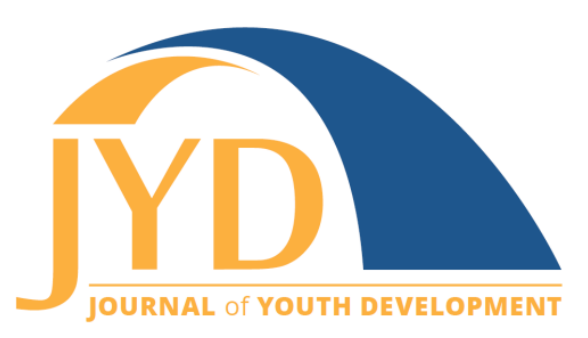

http://jyd. pitt. edu/ | Vol. 13 Issue 3 DOI 10.5195/jyd.2018.598 | ISSN 2325-4017 (online)

\title{
Adolescent Health: Think, Act, Grow (TAG)- A Strengths-Based Approach to Promoting Health in Youth
}

\section{Emily R. Novick}

U.S. Department of Health and Human Services, Office of Adolescent Health emily.novick@hhs.gov

\section{Jamie I. Kim}

U.S. Department of Health and Human Services, Office of Adolescent Health jamie.kim@hhs.gov

\section{Yasmin Mazloomdoost}

U.S. Department of Health and Human Services, Office of Adolescent Health yasmin.mazloomdoost@hhs.gov

\section{Courtney Barthle}

ICF

courtney.barthle@icf.com

\section{Lonna Hays}

ICF

Ionna.hays@icf.com

\section{Abstract}

Adolescent Health: Think, Act, Grow ${ }^{\circledR}$ (TAG) is a national call to action to promote adolescent health and healthy development. Led by the Department of Health and Human Services Office of Adolescent Health and developed with the input of national organizations, it builds on the collective wisdom of youth-serving professionals and seeks to raise the profile of adolescent health in the national discourse. Using TAG, the Office of Adolescent Health conducts outreach and delivers tools and information that support the integration of positive youth development precepts into the ongoing work of federal, state, and local public agencies; youth-serving health, public health, education, and social service professionals and organizations; faith- and community-based organizations; workforce development organizations and employers; and other stakeholders. TAG does not provide a formulaic blueprint for action, but instead

(cc) EY New articles in this journal are licensed under a Creative Commons Attribution 4.0 License. This journal is published by the University Library System, University of Pittsburgh and is cosponsored by the University of Pittsburgh Press. The Journal of Youth Development is the official peer-reviewed publication of the National Association of Extension 4-H Agents and the National AfterSchool Association. 
Adolescent Health: Think, Act, Grow (TAG)

encourages youth-serving organizations to use approaches that are consistent with their mission, objectives, priorities, and tactics. Preliminary evaluation findings indicate interest in the overall concept and resources of TAG, with partners citing the sharing of resources as a primary engagement strategy.

Key words: adolescent health, teen-friendly health care, positive youth development, Office of Adolescent Health

\section{Introduction}

Adolescence is a period of rapid change, growth, development, and learning, and a critical time for setting the course for lifelong health. Behavioral patterns established during this period not only help determine a young person's current health, but also affect their outcomes in adulthood. In 2016, the Lancet Commission described the "triple dividend," in which investments in adolescent health result in benefits now, into adult life, and for future generations (Patton et al., 2016). Others have noted that "research and action on child health and development should evolve from a narrow emphasis on the first 1000 days of life to holistic concerns over the first 8000 days" (Bundy et al., 2018, p. 1). Situating adolescent health and well-being in the national public health landscape creates occasions to harness the impact of the "triple dividend" and recognizes adolescents as a population of opportunity, particularly sensitive to modifications to their experiences (Sawyer et al., 2012).

The mission of the Office of Adolescent Health (OAH) in the U.S. Department of Health and Human Services (HHS) is to improve the health and well-being of adolescents and help them become healthy, productive adults. The $\mathrm{OAH}$ strategic framework addresses five areas:

1. Educating the public and professionals

2. Supporting evidence-based programs and practices

3. Leading through action

4. Promoting multi-sector partnerships

5. Investing in evaluation and research (U.S. Department of Health and Human Services Office of Adolescent Health, 2016b).

Underlying all of OAH's work are positive youth development (PYD) principles. OAH uses a definition of PYD developed by the federal Interagency Working Group on Youth Programs:

PYD is an intentional, prosocial approach that engages youth

within their communities, schools, organizations, peer groups, and

families in a manner that is productive and constructive;

recognizes, utilizes, and enhances young people's strengths; and 
Adolescent Health: Think, Act, Grow (TAG)

promotes positive outcomes for young people by providing

opportunities, fostering positive relationships, and furnishing the

support needed to build on their leadership strengths (Youth.gov,

n.d., Positive Youth Development, para. 1).

\section{Adolescent Health: Think, Act, Grow (TAG)}

In 2014, OAH launched Adolescent Health: Think, Act, Grow ${ }^{\circledR}$ (TAG), a national call to action to improve adolescent health and healthy development. Embracing a PYD approach rooted in youth engagement and stakeholder relationships, TAG builds on previous adolescent health initiatives. TAG was developed with the input of 80 national organizations that work with youth, including the American Public Health Association, the Society for Adolescent Health and Medicine, U.S. Department of Agriculture Cooperative Extension/4- $\mathrm{H}$, and the American School Health Association. These national organizations represented health care, public health, social service, education, community and out-of-school time, and faith-based organizations.

When experts from these diverse sectors discussed what adolescents need to be healthy, consensus formed around common themes that reflect the evolution in the field of adolescent health from a risk-based approach to a strengths-based, PYD approach. The sector discussions led to the development of the Five Essentials for Healthy Adolescents, which encompass findings from the field of adolescent development and form the organizing principles of TAG. Subsequently, each sector group identified action steps to actualize the Five Essentials in their work for, and with, youth. OAH further identified resources to help organizations, professionals, parents and other family members, and adolescents put the Five Essentials into action.

The TAG Five Essentials operationalize the PYD principles of community and family engagement, place-based solutions, fostering positive relationships, leadership development, overall wellness, and transitions to healthy adulthood including health care services. The Five Essentials for Healthy Adolescents are:

1. Positive connections with supportive adults

2. Safe and secure places to live, learn, and play

3. Access to high-quality, teen-friendly health care

4. Opportunities to engage as learners, leaders, team members, and workers

5. Coordinated, adolescent- and family-centered services 
Adolescent Health: Think, Act, Grow (TAG)

\section{Positive Connections with Supportive Adults}

Positive, healthy, and stable relationships with supportive adults encourage healthy development for all adolescents (Moore, Whiney, \& Kinukawa, 2009). For instance, the relationship between children and adult caregivers is a critical influential experience. During adolescence, the nature of the child-adult relationship changes as youth seek independence and peers play an increasingly important role in young people's lives. These shifts result in developmentally-anticipated increases in both positive and negative risk that can create additional opportunities for conflict between adolescents and their parents (Steinberg, 2001; Jellinek, Patel, \& Froehle, 2002). While some amount of conflict is normal, adolescents still rely on parents or caregivers to provide emotional support and set limits, both of which are linked to positive adolescent development (Barnes \& Farrell, 1992; Barber, Stolz, Olsen, Collins, \& Burchinal, 2005). Parents play an essential role in the healthy emotional, physical (Sieving et al., 2017), and social development of teens (Moretti \& Peled, 2004).

Researchers have also recorded the protective implications of effective mentors, which further underscores the significance of an adolescent's healthy relationships with supportive adults. Formal and organic mentor relationships can have value for teens in building other healthy relationships; improving academic performance, peer relationships, and self-confidence; and mitigating stress (Torres, 2013). Unfortunately, teens "most in need of mentors are those least likely to have them" (Erickson, McDonald, \& Elder, 2009, p. 18).

\section{Safe and Secure Places to Live, Learn, and Play}

The physical spaces—schools, neighborhoods, and shared community locations-that teens occupy directly impact the domains of physical, mental, social, and cognitive development (U.S. Department of Health and Human Services, Office of Adolescent Health (HHS OAH, 2018)). For example, youth growing up in neighborhoods characterized by pervasive violence experience compromised interpersonal skills and academic performance as well as other negative effects on their mental, behavioral, and physical health. Researchers note that even when youth are resilient in one domain they may still suffer negative outcomes in other domains (Teitelman et al., 2010).

Emerging efforts to link this Essential with the opportunity to engage youth (Essential 4) are giving rise to the inclusion of youth in the planning and design of their own communities and treating youth as trusted autonomous advisors who are capable of contributing to the long-term well-being of their shared community spaces (Driskell, 2017). 
Adolescent Health: Think, Act, Grow (TAG)

\section{Access to High-Quality, Teen-Friendly Health Care}

"Teen friendly" clinics and health care professionals offer high-quality, inclusive, medically accurate information and resources; facilitate access through convenient locations and teenfriendly scheduling options; maintain confidentiality; engage youth in their own health care decision-making while also engaging parents; and increase youth autonomy over time (HHS $\mathrm{OAH}, 2018)$.

Many youth-particularly those without access to regular health care services-rely on schools as primary sources of health information. One study found that school health centers facilitated access to services that students may not otherwise seek out, particularly counseling and family planning (Soleimanpour, Geierstanger, Kaller, McCarter, \& Brindis, 2010). Students appreciated the confidentiality, free services, youth-focus, and convenience of these centers.

\section{Opportunities to Engage as Learners, Leaders, Team Members, and Workers}

Youth thrive when they have developmentally-appropriate opportunities to learn, lead, and contribute. Research documents the role that sports (Holt, 2007), structured activities, and community service (Eccles, Barber, Stone, \& Hunt, 2003) play in supporting positive academic and relationship outcomes for adolescents. Furthermore, youth involvement in shaping programs and activities provides adolescents with valuable leadership experiences and confidence, and improves the programs for other youth (HHS OAH, 2018). TAG's Game Plan for Engaging Youth offers ideas and approaches for involving youth in governance, leadership programs, advocacy, service, and organizing (HHS OAH, 2016a).

In 2017, OAH hosted a meeting of experts on youth employment and workforce development and added this additional sector to TAG's list of youth-serving professionals that can influence adolescent health outcomes. The TAG Playbook (HHS OAH, 2018) notes that an adolescence that includes work can yield multiple benefits for young people and society. Beyond basic economic contributions and the development of job-related skills, work experience creates opportunities for healthy development such as navigating social situations, improving decisionmaking, and managing increasing levels of responsibility. Working during high school creates advantages for youth now (e.g., lower dropout rates) and into adulthood (e.g., higher wages). 
Adolescent Health: Think, Act, Grow (TAG)

\section{Coordinated, Adolescent- and Family-Centered Services}

Adolescents require care that is uniquely tailored to their developmental stage. Fewer than half of all adolescents receive the recommended number of preventive health care visits and many do not receive all the screening, counseling services, and immunizations recommended for their age group. Additionally, systems for providing services and supports to adolescents are often fragmented, spread across government agencies, nonprofit organizations, health care providers, businesses, and faith-based organizations.

A coordinated, cohesive approach can help close the gaps in care and benefit teens and families by supporting healthy development and promoting better health outcomes for adolescents (HHS $\mathrm{OAH}, 2018)$. The patient-centered medical home model is one way to achieve these goals that shows promise in achieving "better quality, improved experience, and lower costs" for patients (Zutshi et al., 2013, p. iii).

\section{Stakeholder Engagement}

For TAG, stakeholder engagement refers to the process by which members of targeted sectors across the youth-serving spectrum interact with and use TAG's concepts and materials. These sectors include education, workforce, medical and professional organizations, and communitybased providers including communities of faith. Engaging with TAG might include:

- incorporating or leveraging the TAG framework into an organization's framework,

- sharing the TAG framework with staff or board members to develop an organization's vision or strategic priorities further,

- using the TAG framework to provide technical assistance around healthy adolescence to enhance an organization's existing work, and

- disseminating TAG resources to other partners or networks.

$\mathrm{OAH}$ uses the Five Essentials in extensive outreach efforts to engage the original TAG sectors and partners as well as develop new partnerships and relationships that expand TAG's reach and impact. $\mathrm{OAH}$ offers resources and information through TAG to spur stakeholders to take action in support of adolescent health promotion. Successful youth-serving programs across the United States are highlighted on the "TAG in Action" pages of the OAH website.

$\mathrm{OAH}$ also partners with organizations to showcase TAG through social media, webinars, and professional conferences. OAH collaborated on TAG webinars and conference presentations with 
Adolescent Health: Think, Act, Grow (TAG)

the American Public Health Association, U.S. Department of Agriculture's National 4-H Youth Development program, the Association of Maternal and Child Health Programs, and the American School Health Association. These presentations have featured speakers from organizations with innovative approaches to advancing adolescent health in their communities, such as:

- Identity, Inc.: A school-based program providing health care services in Maryland high schools to improve health and education outcomes

- The Ruth and Norman Rales Center: A program to improve access to health care for teens and younger children by better integrating health into educational settings

- Stanford Teen Health Van: A mobile clinic program in the San Francisco Bay area that provides comprehensive health care to at-risk, uninsured, and homeless adolescents

- Providers and Teens Communicating for Health (PATCH): A training program in Wisconsin that trains health care providers and teens to communicate effectively about sensitive health topics

$\mathrm{OAH}$ also develops and disseminates a wide range of resources to engage stakeholders and support them in the implementation of TAG at the local, state, and national levels, including:

- TAG Playbook-offers a framework to address adolescent health with current facts about today's teens, the Five Essentials for Healthy Adolescents, and specific action steps that key stakeholders including youth-serving professionals, family members, and youth can take to promote adolescent health.

- TAG in Action: Successful Strategies-highlights more than 30 successful program strategies used by organizations across the country that address one or more of TAG's Five Essentials in their programs for youth. Featured strategies include:

- Aqui Para Ti/Here for You: A clinic-based health youth development program in Minneapolis, Minnesota, that provides medical care, coaching, health education, and referrals for Latino youth and their families

○ The Trauma-Informed School Learning Collaborative: A New Orleansbased collaborative that provides support to schools as they transform become trauma sensitive and build their capacity to implement, sustain, and improve the delivery of trauma-focused services

- Mount Sinai Adolescent Health Center: A health center in New York City that provides high quality, comprehensive, and inter-disciplinary health and wellness services focused on the unique needs of adolescents and young adults 


\section{Adolescent Health: Think, Act, Grow (TAG)}

○ West Virginia Adolescent Health Initiative: A statewide initiative that supports collaborative, community-based efforts designed to develop the assets youth need to thrive and become successful

- A Place 4 Me: An initiative based in Cuyahoga County, Ohio, working to prevent and end homelessness among youth and young adults (ages 15 to 24), with special emphasis on youth leaving foster care who lack the material and emotional support of a family

- TAG for Teens includes selected resources and tools for teen audiences to get healthy and stay healthy.

- TAG Talks are video presentations by key experts that showcase the latest research on topics such as "The Power of the Adolescent Brain," "The Crisis of Connection for Adolescent Boys," "The Changing Transition to Adulthood," and "Adolescent Substance Use: Prevention, Addiction, and Treatment." TAG Talks include companion resources such as discussion guides for family members and professionals.

- $\underline{\mathrm{OAH} E-u p d a t e s}$ are periodic e-mail communications on topics ranging from sleep, nutrition, and exercise to family connectedness and youth employment.

- Web-based resources on adolescent health topics that address key topics such as healthy relationships (including bullying, dating, friendships, parent-child relationships, and LGBTQ youth), physical health, mental health, reproductive health, and substance use (including alcohol, marijuana, and opioids).

$\mathrm{OAH}$ also uses social media-primarily Twitter-to share content and facilitate communication about TAG. Most content is tagged using \#TAG42mil to represent the 42 million American adolescents that inspired the call to action.

In addition to youth-serving professionals, TAG provides free resources to parents, families, and adolescents that they can use to support teen health, encourage positive youth development, and locate services. The 2016 Lancet Commission on Adolescent Health and Wellbeing report highlighted the critical role of targeted resources for parents and youth in communities as stakeholders that seek to improve adolescent health (Patton et al., 2016). As mentioned above, TAG's Game Plan for Engaging Youth offers ideas for engaging adolescents in promoting their health and healthy development, including approaches for getting youth involved in governance, leadership programs, advocacy, service, and organizing. The Game Plan for Engaging Youth was developed in collaboration with partners with deep expertise on youth engagement, including the Forum for Youth Investment and the Jim Casey Youth Opportunities Initiative. 
$\mathrm{OAH}$ also works closely with the HHS Adolescent Health Working Group, the federal Interagency Working Group on Youth Programs, the National Network of State Adolescent Health Coordinators, and professional associations such as the Society for Adolescent Health and Medicine to share TAG resources and promote the work of organizations that exemplify the Five Essentials.

\section{TAG Evaluation Efforts and Findings}

In 2017 OAH conducted an evaluation of TAG to identify success factors, program strengths, and areas for growth. The TAG evaluation assessed TAG's performance using a sequential mixed methods design in two phases: Phase 1 was initial quantitative analysis of program metrics, and Phase 2 included qualitative data collection and analysis. The evaluation was designed to address three questions:

1. To what extent are TAG project activities aligned with the core objectives of TAG, OAH priorities, and the Healthy People 2020 adolescent health objectives?

2. What is the reach of TAG in the field?

3. To what extent and in what ways are key stakeholders and audiences engaged?

\section{Evaluation Question 1: TAG Alignment}

To assess the extent to which TAG communication and dissemination activities-as described in the Stakeholder Engagement section-aligned with the core objectives of TAG, OAH priority areas, and Healthy People 2020 objectives, the evaluation team conducted an environmental scan of relevant documentation to determine the scope and nature of these priorities and objectives. These documents included the strategic framework of OAH and the Healthy People 2020 standards. As shown in Figure 1, there was strong alignment between TAG activities and the objectives of TAG. When comparing TAG activities to the objectives of Healthy People 2020, two-thirds (64\%) of TAG activities were aligned with at least one Healthy People 2020 objective. The most commonly cited alignments were in promoting afterschool activities (32\%), receiving a wellness check in the previous 12 months (24\%), and adolescents with at least one strong connection to a supportive adult (12\%) (Usher, Jacobson, \& Barthle, 2017). 
Figure 1. Alignment of TAG Communication and Dissemination Activities (Usher, Jacobson, \& Barthle, 2017)

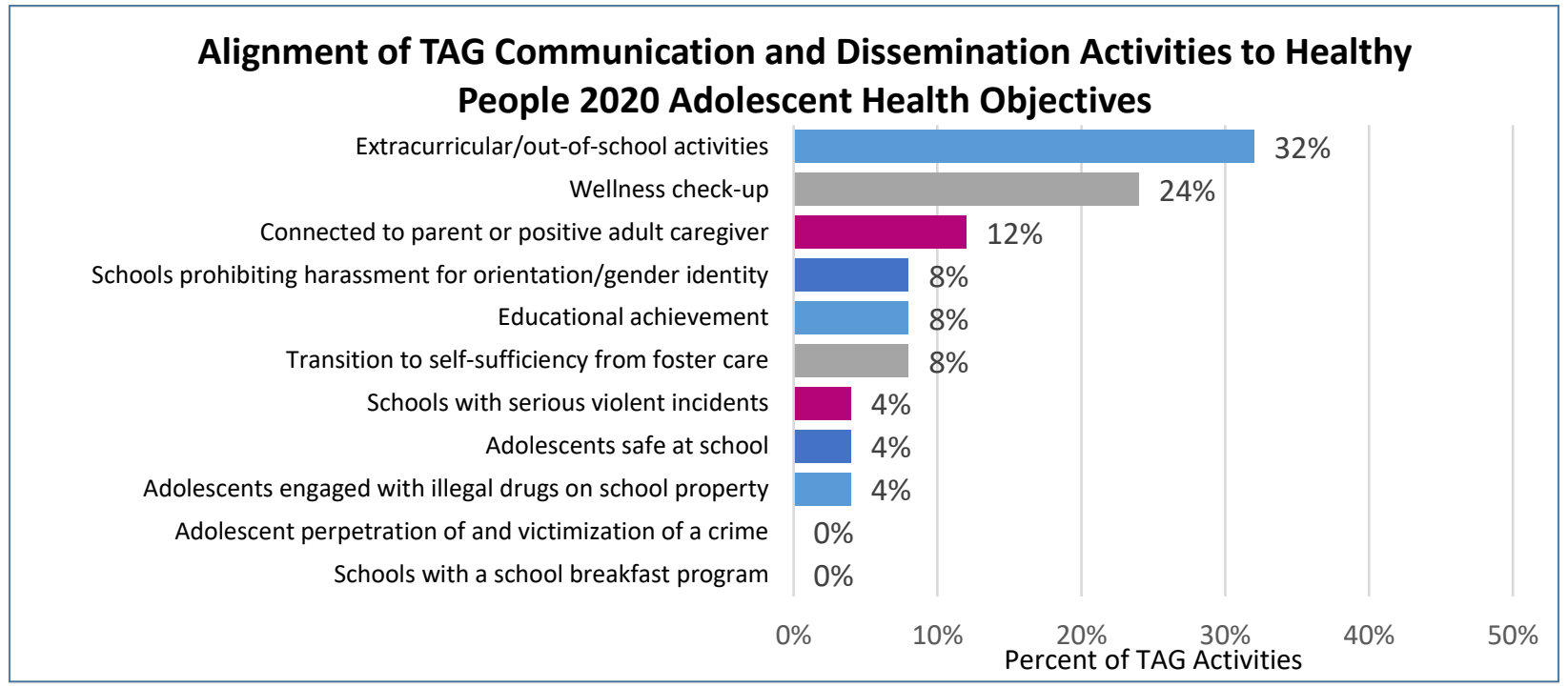

\section{Evaluation Question 2: TAG Reach}

Reach in the field is defined as points of contact and online behaviors within identified groups of stakeholders. Overall participation in the listserv (as measured by new registrations) increased by six percent during the course of the evaluation. Social media impressions-the metric by which content delivery across social media platforms is measured-trended over 3.6 million in the last quarter of the evaluation and over 700 users visited the TAG portion of the website each month, on average (Usher et al., 2017).

\section{Evaluation Question 3: Stakeholder Engagement}

To assess the engagement of stakeholders in the field, the evaluation used semi-structured interviews with HHS regional personnel from eight out of 10 regional offices and surveys of two cohorts of targeted stakeholders, identified by OAH as either "engaged" or "disengaged" with TAG, generally measured by the number of contacts, including sharing of materials and participation in events. Given the modest scope of the evaluation and a low response rate, the analysis included a limited number of surveys.

OAH staff, HHS regional personnel, and both survey groups reported relatively consistent impressions on the reach of TAG in the field, citing the Five Essentials, the TAG Playbook, and web-based services (including email campaigns, webinars, and TAG Talks videos and related 
Adolescent Health: Think, Act, Grow (TAG)

materials) as the most likely services to be referred to targeted stakeholders. Both cohortsthose identified as "engaged" and those identified as "disengaged" (defined as initially interested but not actively engaged with TAG)-reported engagements at similar levels, suggesting that at least some of TAG's penetration is not immediately visible to OAH. This might suggest that TAG has begun to achieve a more organic penetration in the field but more investigation is necessary to adequately address this question.

\section{Community Implications and Adolescent Health}

OAH efforts to engage stakeholders are ultimately intended to put adolescent health on the nation's agenda and change the way communities promote adolescent health. As a national call to action, TAG is intended to provide a framework by which communities, families, and youth can promote healthy development. Collectively, TAG and its resources offer a strategy for changing the narrative on adolescence from one of deficit and challenge to one of opportunity and positivity. Resources like the TAG Playbook provide actionable strategies to "get in the game" and engage with youth across a variety of experiences, opportunities, and settings.

The structural inequities that contextualize the adolescent experience are not fully mitigated by TAG strategies and resources, but can serve as a catalyst for youth-serving professionals, organizations, communities, and families to develop a plan for action. Some states and localities have started on that journey and used the TAG framework to guide their adolescent health efforts. In 2016, the Minnesota Department of Public Health (DPH) began a revision of their Adolescent Health Strategy by hosting a series of listening sessions around the state with youth, educators, parents, public health staff, clinicians, and others. The sessions gave stakeholders an opportunity to identify needs and priorities and provide feedback on what strategies work when promoting adolescent health. DPH credited TAG for providing a spark for thinking about how to organize the input and identify next steps. Ultimately, DPH aligned their new strategic priorities with each of the TAG Five Essentials to reflect a holistic, strengths-based and cross-sector approach to promoting adolescent health (Carr, 2018).

Houston, Texas has also made a significant commitment to promoting adolescent health. Houston's Office of Adolescent Health and Injury Prevention (AHIP) was formed in 2014 to elevate youth voice, emphasize youth health, and ensure youth safety. From the beginning, AHIP committed to taking a positive youth development approach that engages youth in a productive and constructive manner and uses their strengths to improve outcomes for all young people. In 2016, Houston held its first adolescent health conference that included 


\section{Adolescent Health: Think, Act, Grow (TAG)}

representatives from all youth-serving sectors in the city. The conference used TAG as a framework to guide their collective thinking about adolescent health (Shelton, 2017).

\section{Conclusion}

The goal of TAG is to spark actions that support the health and healthy development of America's adolescents. Working with partners in multiple sectors, OAH continues to encourage actions at the national, state, community, and family levels that build on young people's strengths and potential and engage them in promoting and improving their health now and into adulthood. Young people, youth-serving organizations and agencies, family members, and other caring adults are invited to join TAG to raise awareness and take action to promote adolescent health.

\section{How to Get Involved}

Organizations, agencies, and caring adults who work or live with adolescents are invited to join the TAG call to action to raise awareness and promote adolescent health. From recent data on health topics to successful program strategies, TAG has a number of useful resources and tools online and in print that stakeholders, partners, family members, and teens can use to make TAG a reality in their communities. Contact OAH at TAGteam@hhs.gov for more information about getting involved and/or to request printed copies of materials, such as the TAG Playbook, to distribute at staff trainings, meetings, conferences, and other events.

\section{References}

Barber, B. K., Stolz, H. E., Olsen, J. A., Collins, W. A., \& Burchinal, M. (2005). Parental support, psychological control, and behavioral control: Assessing relevance across time, culture, and method. Monographs of the Society for Research in Child Development, 70(4), i-147. doi: 10.1111/j.1540-5834.2005.00365.x

Barnes, G. M., \& Farrell, M. P. (1992). Parental support and control as predictors of adolescent drinking, delinquency, and related problem behaviors. Journal of Marriage and the Family, 54(4), 763-776. doi: $10.2307 / 353159$

Bundy, D. A. P., de Silva, N., Horton, S., Patton, G. C., Schultz, L., Jamison, D. T., \& Sawyer, S.M. (2018). Investment in child and adolescent health and development: Key messages from Disease Control Priorities, $3^{\text {rd }}$ edition. The Lancet, 391(10121), 687-699. doi: 10.1016/S0140-6736(17)32417-0 


\section{Adolescent Health: Think, Act, Grow (TAG)}

Carr, J. N. (2018, February). Minnesota plays TAG. Presented at the Association of Maternal \& Child Health Programs 2018 Annual Conference, Arlington, VA.

Driskell, D. (2017). Creating better cities with children and youth: A manual for participation. New York, NY: Routledge.

Eccles, J. S., Barber, B. L., Stone, M., \& Hunt, J. (2003). Extracurricular activities and adolescent development. Journal of Social Issues, 59(4), 865-889. doi: 10.1046/j.0022-4537.2003.00095.x

Erickson, L. D., McDonald, S., \& elder, G. H., Jr. (2009). Informal mentors and education: Complementary or compensatory resources? Sociology of Education, 82, 344-367. doi: $10.1177 / 003804070908200403$

Holt, N. L. (Ed.). (2007). Introduction: Positive youth development through sport. In Positive youth development through sport (pp. 15-20). New York, NY: Routledge.

Jellinek, M., Patel, B. P., \& Froehle, M. C. (Eds.). (2002). Bright futures in practice: Mental healthVolume I. Practice guide. Arlington, VA: National Center for Education in Maternal and Child Health.

Moore, K. A., Whitney C., \& Kinukawa, A. (2009). Exploring the links between family strengths and adolescent outcomes. Washington, DC: Child Trends. Retrieved from https://www.childtrends.org/publications/exploring-the-links-between-family-strengths-andadolescent-outcomes

Moretti, M. M., \& Peled, M. (2004). Adolescent-parent attachment: Bonds that support healthy development. Pediatrics \& Child Health, 9(8), 551-555. doi: 10.1177/0044118X96028001004

Patton, G. C., Sawyer, S. M., Santelli, J. S., Ross, D. A., Afifi, R., Allen, N. B., . . Kakuma, R. (2016). Our future: A Lancet Commission on adolescent health and wellbeing. The Lancet, 387(10036), 24232478. doi: 10.1016/S0140-6736(16)00579-1

Sawyer, S. M., Afifi, R. A., Bearinger, L. H., Blakemore S. J., Dick, B., Ezeh, A. C., \& Patton, G. C. (2012). Adolescence: A foundation for future health. The Lancet, 379(9826), 1630-1640. doi: 10.1016/S0140-6736(12)60072-5

Shelton, M. (2017). Their future: Strategies for youth leadership and engagement. Presented at the American Public Health Association 2017 Annual Meeting, Atlanta, GA.

Sieving, R. E., McRee, A. L., McMorris, B. J., Shlafer, R. J., Gower, A. L., Kapa, H. M., ... \& Resnick, M. D. (2017). Youth-adult connectedness: A Key protective factor for adolescent health. American Journal of Preventive Medicine, 52(3), S275-S278. doi: 10.1016/j.amepre.2016.07.037

Soleimanpour, S., Geierstanger, S. P., Kaller, S., McCarter, V., \& Brindis, C. D. (2010). The role of school health centers in health care access and client outcomes. American Journal of Public Health, 100(9), 1597-1603. doi: 10.2105/AJPH.2009.186833

Steinberg, L. (2001). We know some things: Parent-adolescent relationships in retrospect and prospect. Journal of Research on Adolescence, 11(1), 1-19. doi: 10.1111/1532-7795.00001 
Teitelman, A., McDonald, C. C., Wiebe, D. J., Thomas, N., Guerra, T., Kassam-Adams, N., \& Richmond, T. S. (2010). Youth's strategies for staying safe and coping with the stress of living in violent communities. Journal of Community Psychology, 38(7): 874-885. doi: 10.1002/jcop.20402

Torres, M. (2013). CAMH study of Big Brothers Big Sisters mentoring program. Centre for Addiction and Mental Health. Retrieved from http://www.camh.ca/en/hospital/about_camh/newsroom/news_releases_media_advisoriesand_b ackgrounders/current_year/Documents/BigBrothers_BigSisters_backgrounder.pdf

U.S. Department of Health and Human Services, Office of Adolescent Health. (2016a). Game plan for engaging youth. Retrieved from https://www.hhs.gov/ash/oah/tag/game-plan-for-engagingyouth/index.html

U.S. Department of Health and Human Services, Office of Adolescent Health. (2016b). Strategic framework FY 2016-2021. Retrieved from https://www.hhs.gov/ash/oah/sites/default/files/20162021_strategicframework.pdf

U.S. Department of Health and Human Services, Office of Adolescent Health. (2018). Adolescent health: Think, act, grow ${ }^{\circledR}$ playbook. Washington, DC: U.S. Government Printing Office. Retrieved from https://www.hhs.gov/ash/oah/sites/default/files/tag-playbook-2018.pdf

Usher, K., Jacobson, M., \& Barthle, C. (2017). Adolescent health: Think, act, grow ${ }^{\circledR}$ (TAG) annual evaluation report: Year one. Rockville, MD: U.S. Department of Health and Human Services, Office of Adolescent Health.

Youth.gov. (n.d.). Positive youth development. Retrieved from https://youth.gov/youth-topics/positiveyouth-development

Zutshi, A., Peikes, D., \& Smith, K., Genevro, J., Azur, M., Parchman, M., \& Meyers, D. (2013). The medical home: What do we know, what do we need to know? A review of the earliest evidence on the effectiveness of the patient-centered medical home model. Princeton, NJ: Mathematica Policy Research. Retrieved from https://pcmh.ahrq.gov/page/medical-home-what-do-we-knowwhat-do-we-need-know-review-earliest-evidence-effectiveness-of-the-patient-centered-medicalhome-model 